\title{
UTAM ZnO Nanostructured Thin Film CO Sensor
}

\author{
Ali Jasim Mohammed ${ }^{1}$, Gerhard Wilde ${ }^{2}$ \\ ${ }^{1}$ Department of Physics, College of Science, Al-Mustansiriyah University, Baghdad, IRAQ. \\ Spiritjabir63@yahoo.com \\ ${ }^{2}$ Institute of Material Physics, University of Muenster, Muenster, GERMANY.
}

\begin{abstract}
Zinc oxide nanowires/nanobelts thin films were prepared by atomic layer deposition (ALD) of $\mathrm{Zn}$ on Cr-glass substrates using an ultrathin aluminum membrane (UTAM). ZnO nanostructured based $\mathrm{CO}$ - gas sensing thin films were formed, and the morphologies of these films were investigated by scanning electron microscopy (SEM). The sensing response of the films toward CO gas at operating temperatures in the range of $(25,75,125,150$, and $175)^{\circ} \mathrm{C}$ was studied. The set-up designed to measure the gas sensing ability due to the change of the resistivity related to the gas addition, the electrical resistivity as well as the gas sensing properties of the $\mathrm{ZnO}$ nanostructured thin films changed significantly with the operating temperatures. The sensitivity increased with increasing operating temperature, particularly above $150^{\circ} \mathrm{C}$.
\end{abstract}

Key words: Zinc oxide thin films, UTAM, nanostructured thin films, gas sensors, ALD.

\section{Introduction}

Most of gas sensors based on zinc oxide thin films have been fabricated for detecting toxic and hazardous gases such as $\mathrm{H}_{2}, \mathrm{CO}_{2}, \mathrm{CO}$, $\mathrm{H}_{2} \mathrm{~S}$, and $\mathrm{NO}_{2}$ [1-6]. Pure or doped $\mathrm{ZnO}$ or composites of $\mathrm{ZnO}$ with other materials have been used for detecting gases, in order to enhance the response and recovery towards both the oxidizing and the reducing analyte [7]. Furthermore, sensors based on $\mathrm{ZnO}$ nanobelts were found to be highly selective in their response to NO. The mechanism of improving the response to $\mathrm{H}_{2}$ based on annealing has been proposed and discussed [8]. CO sensing properties were investigated for the grown structures, and the response of comb-like structures was found to be 1.4 at $75{ }^{\circ} \mathrm{C}$, while belts and mixtures of belts and rod like structures did not show any response [9]. The influence of $\mathrm{Mn}$ on trimethylamine (TMA) and ethanol sensing properties has been reported [10]. ZnO nanorod sensors with embedded $\mathrm{Ag}$ nanoparticles $\mathrm{ZnO}$ nanorod sensors have shown long-term stability and exhibited highly enhanced gas sensing performance in their response and selectivity for detecting ethanol vapor. High sensitivity, fast recovery, and reliability have been achieved by $\mathrm{Al}$ doped $\mathrm{ZnO}$ prepared by RF magnetron sputtering. The characterization of sensing properties for detecting $\mathrm{NO}_{2}$ and $\mathrm{CO}$ gases by nanocomposite thin films such as $\mathrm{CdO}-\mathrm{ZnO}, \mathrm{ZnO}-\mathrm{SnO}_{2}$, and $\mathrm{ZnO}-\mathrm{TiO}_{2}$ have been studied [11, 12].

The aim of this work is to produce high-quality nanostructured $\mathrm{ZnO}$ thin films by ALD using UTAM mask on a glass substrates. Special attention paid to form nanostructured thin films as well as to examine these films concerning the $\mathrm{CO}$ gas sensing properties. In this work, the authors produced a fast, strong and repetitive response $\mathrm{ZnO}$ sensor for $\mathrm{CO}$ gas detection which can be fabricated at low coast.

\section{Experimental Work}

Template of Ultra Thin Alumina Membranes (UTAM) first prepared by anodization, it was made under a constant cell potential condition (voltage $=40$ volt) in oxalic acid solution, after that several chemical procedures was carried out to obtain UTAM masks.

Then zinc oxide nanostructured thin films are produce by atomic layer deposition (ALD) , after the deposition process was finished the samples were ready for synthesizing and characterizing measurements.

\section{Characterization and Measurements}

The surface morphology of the films was studied by a (NOVA NANOSEM 230) scanning 
electron microscope (SEM) with field emission cathode. Gas sensing studies have been carried out using a stainless steel chamber with multiple inlets, outlets and feed throughs connected to the electrometer (KEITHLEY 4200-SCS). The chamber was evacuated by a rotary pump (EDWARDS), and solenoid valves served to switch the test gas on and off Figure 1).
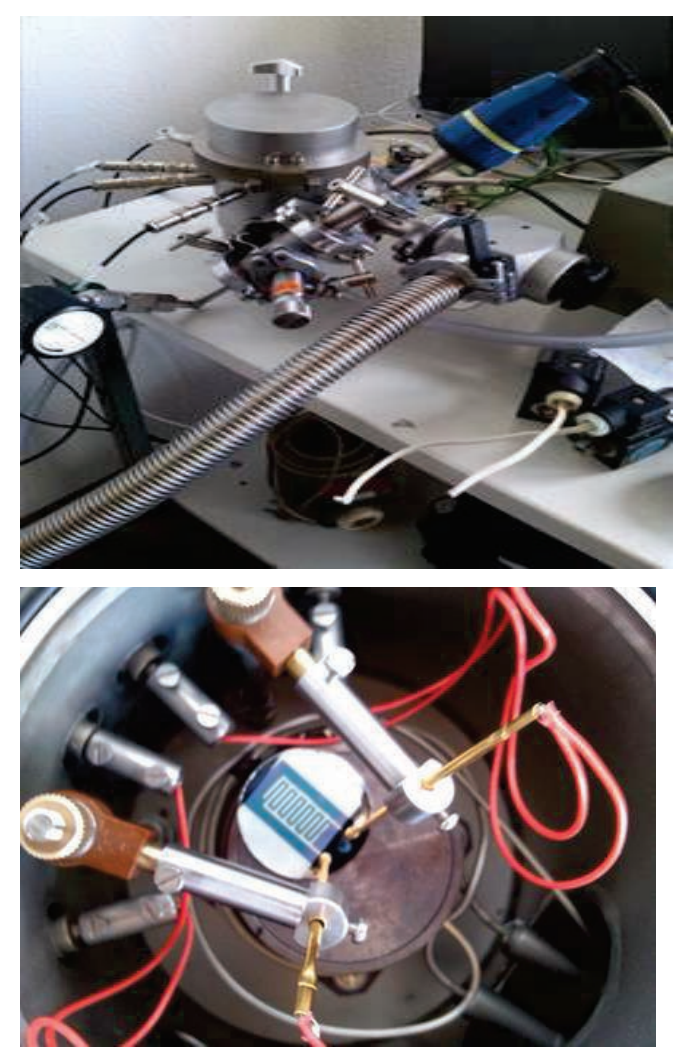

Fig. 1. The setup of the sensing equipment.

\section{Results and discussion}

The analysis of the surface morphology of the prepared $\mathrm{ZnO}$ thin films was carried out by scanning electron microscopy (SEM). Figure (2) shows the micrograph of the $\mathrm{ZnO}$ thin films deposited on the glass substrate by ALD on the UTAM mask. The micrograph shows the periodically arrangement different types of nanostructures. The figure clearly shows a regular distribution of hexagonal bee cell with a nanostructure.

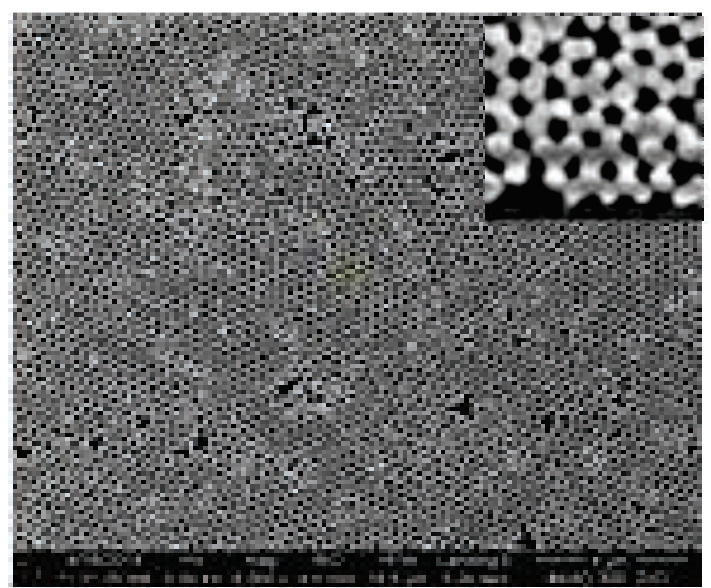

Fig. 2. SEM photo of the beehave-like structure of the $\mathrm{ZnO}$ deposited film on the UTAM mask.

Increasing the temperature of the sensing measurements enhance the results, the sensing current increased instantaneously to a maximum value, which was maintained at the maximum current upon exposure to $\mathrm{CO}$ and recovered completely to the initial value upon the removal of $\mathrm{CO}$. The sensor shows high stability during repeated test cycles. The significant enhancement in the response of the $\mathrm{ZnO}$ nanostructured thin films to $\mathrm{CO}$ gas by increasing the temperature was attributed to the decrease of the contact resistance between the grains. Figures (3-7) show the increasing in sensing current with the temperature increase in the range of $(75-175)^{\circ} \mathrm{C}$ respectively by a step of $25^{\circ} \mathrm{C}$.

Fig. 3. Sensing current at $75^{\circ} \mathrm{C}$.

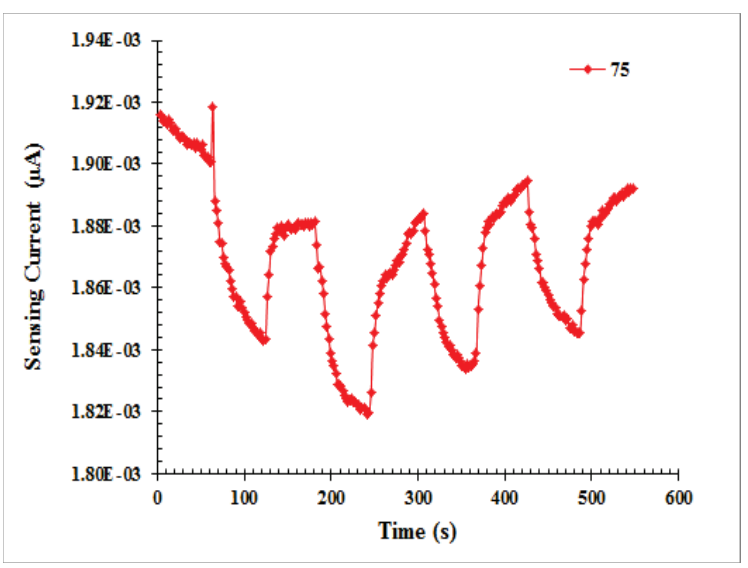




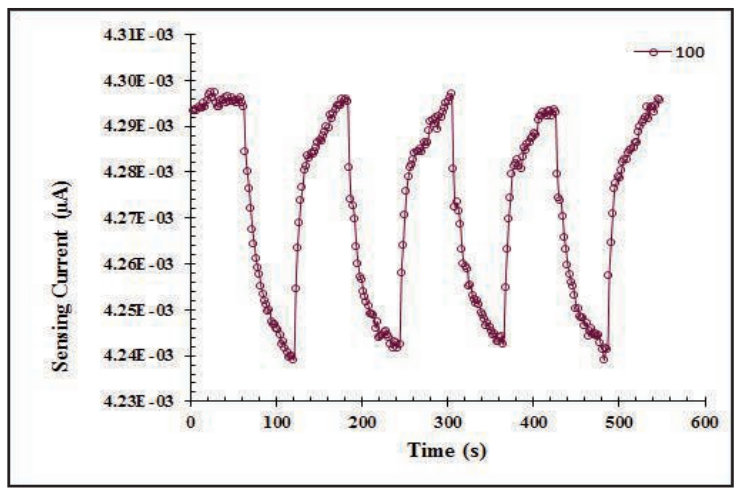

Fig. 4. Sensing current at $100^{\circ} \mathrm{C}$.

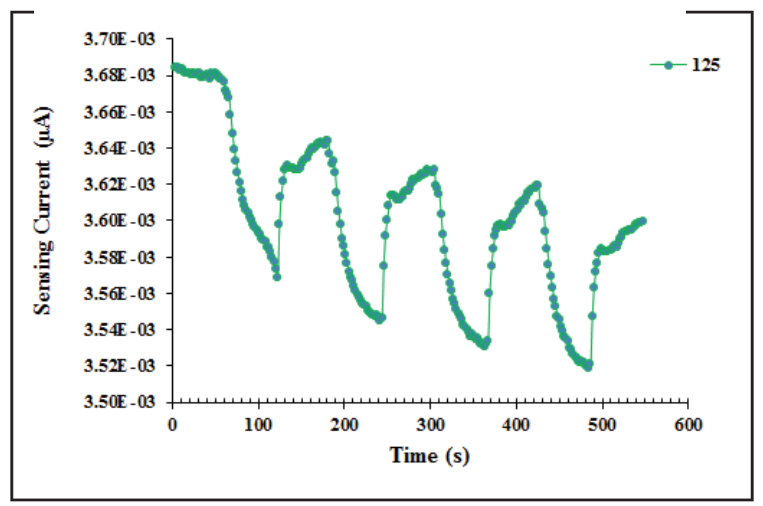

Fig. 5. Sensing current at $125^{\circ} \mathrm{C}$.

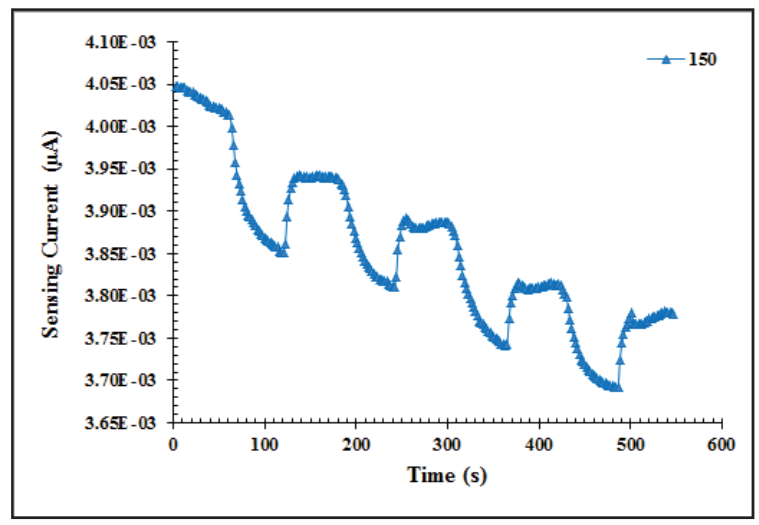

Fig. 6. Sensing current at $150^{\circ} \mathrm{C}$.

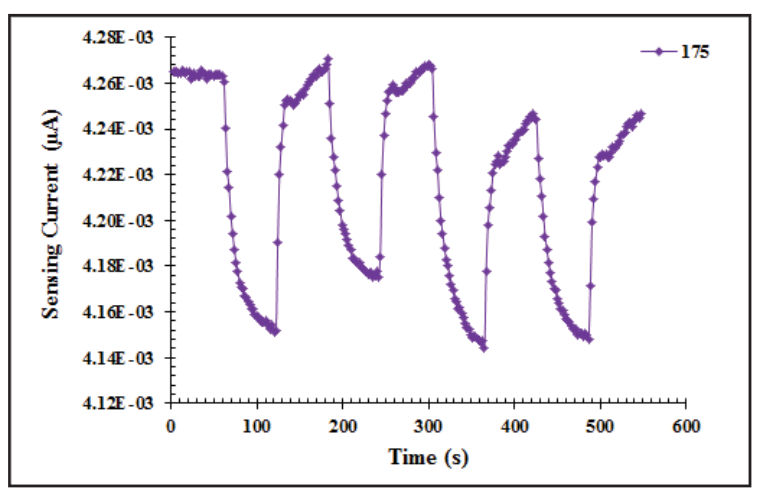

Fig. 7. Sensing current at $175^{\circ} \mathrm{C}$.
The sensitivity and typical response of $\mathrm{ZnO}$ nanowires and nanobelts to $\mathrm{CO}$ gas measured at different temperatures are shown in figures 8 and 9 . Here, the sensitivity $(S)$ is defined as:

$S=\frac{I g-I a}{I a} \times 100$

Where, $I_{g}$ and $I_{a}$ are the sensing currents in the presence of gas and in air respectively.

The sensitivity of the prepared films was increase with the raise of the operating temperature because it provides a reliable conditions for more chemical interactions between the additive gas and the oxygen vacancies in the surface layer, the results illustrate in the Figure 8

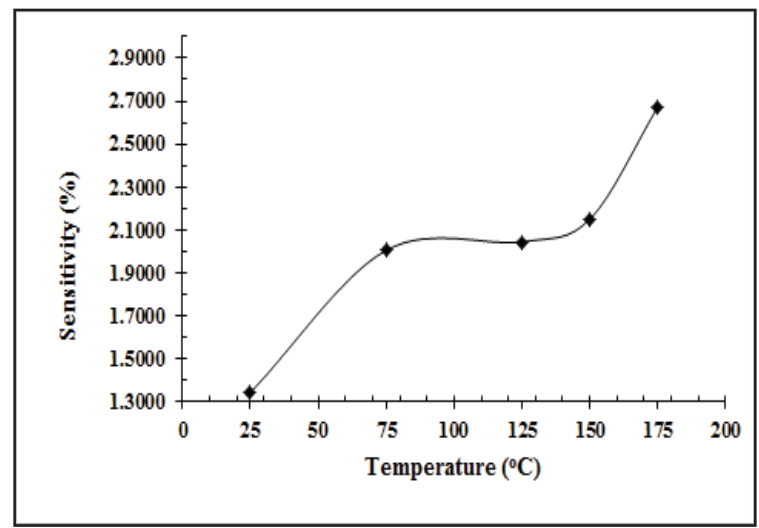

Fig. 8. Sensetivity various with the temperature.

The response of the film towards the CO sensing has been shown in the figure 9 .

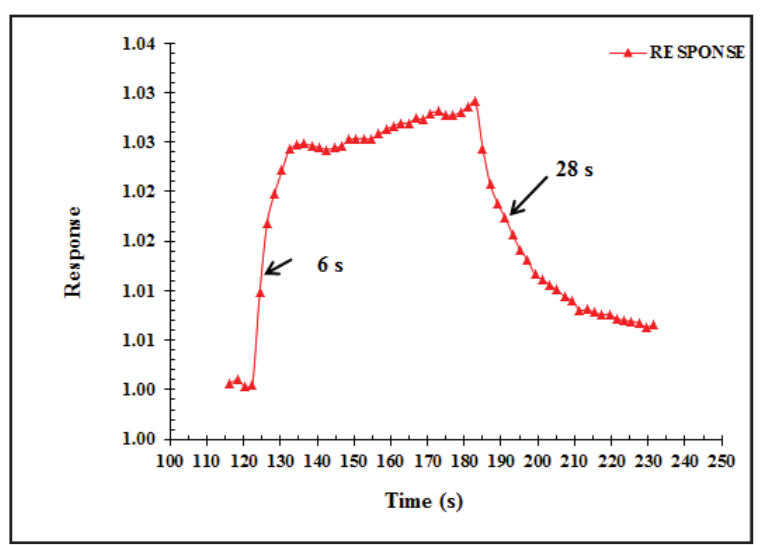

Fig. 9. Response of the prepared film. 


\section{Conclusion}

To conclude, $\mathrm{ZnO}$ thin films have been synthesized and deposited on the glass substrates. Nanostructured thin films are grown by optimizing the deposition parameters of the ALD system. The present work discusses and compares the sensing characteristic of $\mathrm{ZnO}$ nanostructured films as $\mathrm{CO}$ sensors. The deposited films are characterized concerning their microstructure and concerning their sensing behavior towards $\mathrm{CO}$ at different operating temperatures $25,75,125,150$ and $175 \mathrm{oC}$. The sensor response and recovery time of deposited films on glass substrates is found to increase with the temperature. However, considering the response and recovery time characteristics, $\mathrm{ZnO}$

\section{References}

[1] J. X. Wang, X. W. Sun, Y. Yang, K. K. A. Kyaw, X. Y. Huang, J. Z. Yin, J. Wei, and H. V. Demir, Free-standing $\mathrm{ZnO}-\mathrm{CuO}$ composite nanowire array films and their gas sensing properties, Nanotechnology 22 (2011) 325704.

[2] A. B. Yadav, C. Periasamy, , S. Bhaumik, and Jit, Hydrogen gas sensing properties of $\mathrm{Pd} / \mathrm{ZnO}$ thin films grown on $n-S i<100>$ substrates at room temperature by thermal evaporation and sol-gel techniques: A comparative study, Indian Journal of Pure \& Applied Physics 51 (2013) 792-799.

[3] R. M. Agrawal, G. T. Lamdhade, N. G. Balsere, A. S. Wadtkar, T. S. Wasnik, R. V. Joat, and R. V. Waghmare, Fabrication of multilayer thin film sensor (MgO-TiO2-ppy) for sensing application of $\mathrm{CO} 2$ gas, International Journal of Basic and Applied Research, Special Issue (2012) 256258.

[4] S. W. Choi, and S. S. Kim, Room temperature $\mathrm{CO}$ sensing of selectively grown networked $\mathrm{ZnO}$ nanowires by $\mathrm{Pd}$ nanodot functionalization, Sensors and Actuators B 168 (2012) 8-13.

[5] P. S. Shewale, B. N. Kamble, A. V. Moholkar, J. H. Kim and M. D. Uplane, Influence of substrate temperature on $\mathrm{H} 2 \mathrm{~S}$ gas sensing properties of nanocrystalline zinc oxide thin films prepared by advanced spray pyrolysis, IEEE Sensors Journal 13 (2013) 1992-1998.

[6] S. T. Shishiyanu, T. S. Shishiyanu, and O. I. Lupan, Sensing characteristics of tin-doped $\mathrm{ZnO}$ thin films as NO2 gas sensor, Sensors and Actuators B 107 (2005) 379-386. nanostructured sensors at an operating temperature of $175 \mathrm{oC}$ shows the best sensing performance.

\section{Acknowledgment}

This work was supported by the German Academic Exchange Service [DeutscherAkademischerAustauschDienst (DAAD)] grant funded (No. A/13/04255)

[7] M. Z. Ahmad, J. Chang, M. S. Ahmad, E. R. Waclawik, and W. Wlodarski, Non-aqueous synthesis of hexagonal $\mathrm{ZnO}$ nanopyramids: gas sensing properties, Sensors and Actuators B (2013) 286-294.

[8] K. Vijayalakshmi, K. Karthick, and D. Gopalakrishna, Influence of annealing on the structural, optical and photoluminescence properties of $\mathrm{ZnO}$ thin films for enhanced $\mathrm{H} 2$ sensing application, Ceramics International 39 (2013) 4749-4756.

[9] M. Amin, U. Manzoor, M. Islam, A. S. Bhatti, and N. A. Shah, Synthesis of ZnO nanostructures for low temperature CO and UV sensing, Sensors 12 (2012) 13842-13851.

[10] D. Sivalingam, J. B. Gopalakrishnan, and J. B. B. Rayappan, Structural, morphological, electrical and vapour sensing properties of $\mathrm{Mn}$ doped nanostructured $\mathrm{ZnO}$ thin films, Sensors and Actuators B 166-167 (2012) 624-631.

[11] H. Karami, Investigation of sol-gel synthesized CdO-ZnO nanocomposite for CO gas sensing, Int. J. Electrochem. Sci., 5 (2010) 720-730.

[12] Z. Chen, S. Li, and W. Zhang, Pulse electrodeposition of $\mathrm{ZnO} / \mathrm{SnO} 2$ composite films: growth mechanism, structural and optical studies, Journal of Alloy and Compounds 557 (2013) 274-278.M. Mouse, D. Duck, The Beagle Boys for President, Journal of Applied Nonsense 13, 123-134 (2011); doi: 10.1234/s10000 